\title{
Mapping trends in educational-leadership research: A longitudinal examination of knowledge production, approaches and locations
}

Dol:

10.1177/17411432211030758

\section{Document Version \\ Accepted author manuscript}

Link to publication record in Manchester Research Explorer

Citation for published version (APA):

McGinity, R., Heffernan, A., \& Courtney, S. (2022). Mapping trends in educational-leadership research: A longitudinal examination of knowledge production, approaches and locations. Educational Management Administration and Leadership, 50(2), 217-232. https://doi.org/10.1177/17411432211030758

Published in:

Educational Management Administration and Leadership

\section{Citing this paper}

Please note that where the full-text provided on Manchester Research Explorer is the Author Accepted Manuscript or Proof version this may differ from the final Published version. If citing, it is advised that you check and use the publisher's definitive version.

\section{General rights}

Copyright and moral rights for the publications made accessible in the Research Explorer are retained by the authors and/or other copyright owners and it is a condition of accessing publications that users recognise and abide by the legal requirements associated with these rights.

\section{Takedown policy}

If you believe that this document breaches copyright please refer to the University of Manchester's Takedown Procedures [http://man.ac.uk/04Y6Bo] or contact uml.scholarlycommunications@manchester.ac.uk providing relevant details, so we can investigate your claim.

\section{OPEN ACCESS}


Educational Management

Mapping trends in educationalAdministration \& Leadership $1-16$

(C) The Author(s) 2021 leadership research: A longitudinal examination of knowledge production, approaches and locations

\section{(c) (1)}

Article reuse guidelines: sagepub.com/journals-permissions DOI: I0.1।77/|74||4322|I030758 journals.sagepub.com/home/ema

@SAGE

\author{
Ruth McGinity, Amanda Heffernan (1) \\ and Steven J Courtney
}

\begin{abstract}
The field of educational-leadership research has broadened over the last 50 years, with diverse knowledge-production traditions (e.g. functionalist and critical); audiences (e.g. practitioners, researchers and policymakers) and preferred sites of publication. In this article, we trace how the objectives, methods, claims and relative significance of educational-leadership research, and the identities and epistemological assumptions of educational-leadership researchers, are changing over time.

We systematically and manually analysed trends in educational-leadership research through keyword searches across all journal publication sites over 50 years, exploring researchers' contributions, epistemological positioning and journal choices. We also explored the balance between empirical and conceptual scholarship, geographical location and use of theory. We found that critical educational-leadership research is common across the international field but is more likely to be published in high-ranking generalist education journals or lower-ranking educationalleadership-focused journals. Our research contributes a novel, robust and, significantly, relatively wide-ranging empirical basis to identify key trends, gaps and silences within the field of educational-leadership research over time. Our research enables better understanding of the areas that are potentially under-researched and the ways the field might be creating and reproducing power dynamics in research.
\end{abstract}

\title{
Keywords
}

Knowledge production, knowledge producers, educational management administration and leadership, educational leadership, longitudinal trends, critical and functionalist epistemology, field mapping 


\section{Introduction}

The field of educational leadership, management and administration (ELMA) research has diversified and developed in size, scope and impact over the last 50 years (Gumus et al., 2021; Hallinger and Kovacevic, 2019). Concomitantly, interest has grown in mapping and typologising its knowledge base, its methodological and conceptual approaches and, increasingly, knowledge-production locations (Erickson, 1979; Gunter, 2016; Gunter and Ribbins, 2002; Hallinger, 2020; Heck and Hallinger, 2005; Murphy et al., 2007; Oplatka, 2009; Ribbins and Gunter, 2002; Thomson, 2017). Systematic and bibliometric reviews have increased as researchers attempt to codify knowledge production in the field using techniques to assess volume, growth trajectory, geographic distribution, citation and co-citation practices, thematic foci, epistemological positioning and theory use (for example, see Castillo and Hallinger, 2018; Gumus et al., 2018; Hallinger, 2011, 2020; Hallinger and Chen, 2015; Hallinger and Kovačević, 2019, 2021; Oplatka and Arar, 2017; Walker and Hallinger, 2015). In this article, we contribute to this literature through our mapping of knowledgeproduction traditions, trends and trajectories. We identify the ways in which the field is making sense of its own development and locate and analyse gaps in recent scholarship into field mapping. We treat knowledge production as partial and epistemologically located (Gunter, 2006), and apply this analytical principle to our data.

The 50th anniversary edition of this, currently the world's highest-ranked journal in the field of ELMA according to Google Scholar Metrics and the Web of Science impact factor scores, provides a salient opportunity to consider the extent to which systematic approaches to revealing the stateof-the-field are partial, incomplete or obfuscated and why this matters in terms of (a) knowledge production and (b) claims made about the significance of particular research agendas for the field.

We undertook a systematic mapping and used a critical-synthesis approach to examine the field's evolution over 50 years using the Scopus web-database and keyword searches. This approach is distinctive from other, recent mapping projects where search parameters have included journal-specific criteria (Hallinger and Kovacevic, 2019, 2021) or geographic location criteria (Hallinger, 2020) but seldom non-journal-specific keyword searches. Their use enabled us to locate a broad range of research from beyond traditional ELMA journals, revealing research missing from other mappings. Our research question asked what the key trends characterising the field of educational-leadership research are over the last 50 years concerning, for instance, where research is published, where it is located, and its knowledge tradition.

Our analysis reveals that, over the last 50 years, the proportion of empirical research has increased and methodological approaches (of data generation and analysis) have diversified, yet the field is persistently under-theorised. Additionally, the deployment of the word leadership has expanded during this period, even as it has become conceptually weakened through successively sloughing off first administration and then management. Third, most research remains from and/or about the global north - this includes Australia and New Zealand - see Royal Geographical Society (undated). Finally, we identify increasing research situated in the critical-epistemic tradition, which is more often found in general education rather than leadership-specific journals.

Our contribution is methodological, through demonstrating the usefulness of a mixed-methods, non-bibliometric approach to field mapping that instead foregrounds knowledge traditions and their implications. Our contribution is also empirical, through interrogating field outputs longitudinally. To our knowledge, no other analysis has compared five snapshots over 50 years. Hallinger and Kovačević (2021), for instance, sample data from a similar range, but analyse it together. We see these contributions as integral to this special issue's celebration of Educational 
Management Administration \& Leadership's 50-year anniversary: our findings locate EMAL as a field leader, publishing diverse as well as important research. Nonetheless, well-theorised critical research in educational leadership (see 'Epistemic traditions' section below) is more likely to be published in generalist education journals.

\section{Mapping ELMA: key trends and dimensions}

Here, we identify and synthesise the main trends and key dimensions in prior ELMA field mappings. This illuminates the gaps and distortions, which we address in our analysis.

Research whose object of analysis is the field itself is common, since establishing the state-ofthe-art within a field is a prerequisite to contributing to it (Erikson, 1979). Within ELMA, knowledge production has been mapped through several dimensions since the 1970s; these include timeframe (1970s-1980s, 1990s-2000s, post-2010); geographical location (of either/both the research and researchers); approach (systematic and bibliometric reviews, science-mapping, critical syntheses); type and scope (inclusion and exclusion criteria of type); methodologies (particularly quantitative vs qualitative approaches, empirical or conceptual); and epistemic traditions (particularly regarding critical and functional knowledge domains). Few of these mappings include all, but most include some of these dimensions, which, since they are adopted in subsequent mappings, consequently structure as well as reflect how the field understands itself, and codifies the knowledge it produces. We now consider each of these dimensions.

\section{Dimensions of mapping knowledge production}

Below, we set out the four main dimensions that characterise mapping scholarship within ELMA (timeframe; location; type and scope; and epistemic traditions) as well as identify some of the methodological, empirical and conceptual limitations of these dimensions.

Timeframe. The use of timeframe is one of the only dimensions that all field-mapping scholarship shares. This establishes a common principle regarding inclusion and exclusion criteria, which is simple to classify and acknowledges field-development phases. ELMA mappers agree that whilst conceptualisations have shifted concerning the descriptive and analytical labelling of educational practices attributed initially to management and administration and latterly to leadership, these paradigmatic shifts align with temporal classifications (i.e. broadly speaking, management and administration from the 1960s-1990s and leadership from the 1990s). Most reviews take into account this shifting landscape and use the earlier dates to indicate ELMA's founding (Wang et al., 2017; York-Barr and Duke, 2004). Secondly, mappings are influenced by changing priorities within these broad timeframes: Hallinger and Kovačević (2019), for instance, suggest that earlier (1960s onwards) mapping scholarship focused upon types of knowledge and topics, and that midera mapping (1990s) developed the criteria against which a 'sound' knowledge base might be described (2019: 338).

Location. Identifying geographic regions in which knowledge is produced and located is increasingly significant in mapping scholarship, as greater attention is paid to the consequences of globalisation for knowledge exchange and production (Hallinger and Chen, 2015). This dimension is two-fold, concerning first where the knowledge bases are and, second, where researchers are located, and how claims about regional influence and differentiation are made in relation to this. 
In a series of papers published between 2015 and 2019, Hallinger reviewed the literature using bibliometric and science-mapping to identify and establish the field's knowledge base according to region $(2015,2019)$. Further studies focused more specifically on Asia as an 'emerging region' identified by Hallinger (2020), leading to more research which contributed to the ELMA knowledge base. Hallinger (2020) undertook bibliometric analyses to identify thematic research trends, and (co)citation analysis to locate the most highly cited researchers in this 'emerging region'. He found that the growth trajectory in Asia was distributed unevenly between regions, with a few scholars identified through the co-citation analysis representing much of the cited scholarship in the region. What this analysis obscures is that most of these scholars are male academics originally from the global north who have relocated to Asia (with some holding multiple visiting posts across the region). This is important because it leads to an over-statement of internationalisation. For example, Hallinger and Kovačević (2021: 10, table 1) show that seven of the 20 most highly cited EMAL articles from the last 50 years are from outside the UK and North America. However, Hallinger's own work accounts for four of these outputs. One more of the seven was produced by Alma Harris (2013) whilst she was located in Malaysia, although nothing about her article reflects this location. Such instances might explain why particular research paradigms and approaches are identified as dominant and significant in this bibliometric analysis. Thus, knowledge production is rooted in and connected to knowledge producers, and systematic or bibliometric reviews and analyses are also products of this relationship.

Type and scope. Several recent reviews of the ELMA field restrict the search criteria, whether via Scopus, the Web of Science, ERIC or Google Scholar, to domain-specific journals (e.g. Hallinger and Kovačević, 2019). Some reviews specifically identify citation practices in a particular university or faculty and generally fall within the domain of library or information studies (Condic, 2015). However, those reviews explicitly addressing ELMA majoritively include journals as the main sites of publication and specifically ELMA-dedicated journals (Hallinger, 2020; Jackson, 2019). Two main, interconnected limitations arise therefrom: first, most of these domain-specific journals are located in the global north (the USA has the most) and, second, they reflect specific knowledge traditions that have developed out of these geographical regions and are reflected in the reviews' findings. For example, Hallinger and Kovačević (2019) identify 22 educational administration (EA) journals, most of whose editorial boards are USA-based, and where the key areas of research identified are school effectiveness and improvement; leading school culture; and leadership for learning and leading teachers, all of which represent a normatively functionalist framing of the research and analysis of the practices and processes within ELMA. Bibliometric reviews therefore exclude research published outside of this majoritively USA-based journal search and reproduce its knowledge base: this obscures the importance of ELMA research which is published outside of domain-specific journals (and particularly areas where there is conceptual overlap with other fields such as sociology, economics, philosophy, policy and politics, for example). Bibliometric approaches also conflate 'highly cited' with 'significant'. Arguments can gain traction because they speak to, are located within, and support further developments to a recognised conceptual architecture. Author co-citation approaches, i.e. bibliometric, therefore enable grounds for self-certificating significance that are simultaneously recursive and extrapolatory.

Most ELMA reviews have identified more empirical than conceptual research in these outputs (e.g. Hallinger, 2020; Hallinger and Chen, 2015; Oplatka and Arar, 2017); this is true against most variables that might be included with a bibliometric review (location, timeframe, epistemic tradition). These reviews have paid less attention to methodologies used across the field or to the extent 
to which particular knowledge-production techniques are deployed, such as the use or type of theory (Hallinger, 2020).

\section{Epistemic traditions}

ELMA research may be classified according to its epistemic location (see e.g. Eacott, 2017). A major strand of Gunter's intellectual project and contribution to the field has been to map and conceptualise these epistemic traditions and communities, arguing that they inform the reasons for producing knowledge, what counts as knowledge and who counts as knowledgeable (see e.g. Gunter, 2005, 2016; and Gunter and Ribbins, 2002). Whilst Gunter has revised and honed the precise terms used throughout her career, there has been a consistent thread concerning the identification of two major strands, broadly comprising functional and socially critical approaches (Gunter, 2012). Functionalist research offers

solutions to identified problems, and this can be descriptive through empirical work that leads to understanding (e.g., Day et al., 2000; Edmonds, 1968; Hall et al., 1986, and/or normative through the promotion of a particular idea about how a problem should be solved (e.g., Davies, 2006; Harris, 2008; Stoll and Fink, 1996)." (Gunter, 2012: 338-339)

Functionalism constructs the social world as amenable to significant improvement, largely understood as enhanced effectiveness, once the observable and measurable dysfunctions or barriers to success have been removed. Socially critical research sees these dysfunctions not simply as 'a glitch in an otherwise benevolent system, but [as] a result of the inequalities built into society' (Raffo and Gunter, 2008: 401). Approaches are required to 'challenge existing power structures and inequality and enable democratic development' (2008: 401). Such approaches are much more often explicitly theorised. Gunter's framework has been taken up across the field (e.g. Courtney and McGinity, 2020a) or used to posit new categorisations (Eacott, 2017) and is useful for conceptualising purposes and locating knowledge claims.

Few of the major reviews of ELMA pay explicit attention to these epistemic traditions. Hallinger and Kovačević (2021) come closest, employing author co-citation analysis (ACA) to produce what they call 'schools of thought' (2021: 14). However, in their analysis, research traditions are reduced to areas of interest and shorn of their epistemological underpinnings. This means that scholars such as Gunter and Coleman are categorised together, as focusing upon 'the social justice issues raised in the reform of education' (2021: 14); this elides their differences in approach (socially critical versus humanistic).

Most of the major field reviews are located within the knowledge domain of functionalism; bibliometric reviews and co-citation analyses reflect the preference for and privileging of research within that domain (Hallinger, 2020). Eyal and Rom (2015) are notable exceptions: through surveying the ELMA literature base in Israel between 2000 and 2012, they identify three key research areas located within different epistemic traditions (impact of leadership on school effectiveness; politics of leadership; and alternative lenses of leadership).

Gunter's field mappings (e.g. 2016) share a critical disposition with a set of contributions that include Wilkinson and Eacott (2013); Niesche (2018) and Thomson (2017). These critical mappings are rarely empirical, and if they are, they focus on specific issues such as methods (see Thomson, 2017) or on specific journals (see Wang et al., 2017). 
Educational Management Administration \& Leadership XX(X)

\section{The study}

Our study had three distinctive empirical objectives: the first was to capture longitudinality trends in educational-leadership research over a 50-year period. Whilst others (e.g. Szeto et al., 2015) have drawn their sample from a range of years that might have yielded longitudinal data, they produced only one batch of articles and so did not aim at comparison. The second empirical objective was to locate educational-leadership research regardless of publication site. Here, we were motivated by an obvious methodological limitation in the starting point of all other similar mappings, namely, the identification of key journals from which to sample. The third objective was to use researcher interpretation rather than software to better capture meaning.

Our sampling range of 50 years meant that we needed to reduce the document selection to enable analysis without dedicated software. To achieve this, we sampled in batches of one year every decade. Our focus is on educational leadership rather than management and/or administration; this produces some of the effect seen in the sample whereby the numbers returned increase notably over the period. Accordingly, we are focused on the story of the rise of educational leadership as a field and of its changing features, rather than of the state of the whole ELMA field. Similarly, we excluded terms such as deputy headteacher, again, to retain focus.

Other ways in which we sought to focus our search included using only Scopus as a database. We understood that this would omit certain outputs, but methodologically, this approach enabled blind peer-reviewed scholarship to be returned. We performed five searches of the database at intervals of a decade, looking for articles using the following command: TITLE (educational OR school OR principal* AND leader*). The use of the asterisk returns all words based on that root, i.e. leader* returns leaders, leadership, etc. We then skimmed the abstracts of the returned papers and filtered out those that did not focus on educational leadership, reducing the total sample by 19 papers. For example, we filtered out an article about leaderboards in educational games, which met the search terms but did not meet the scope of this study. Further reductions were made for inaccessible articles that could not be viewed via any of our three different institutional library access options, or beyond (such as independent research repositories), for a total of four articles across the five decades. The final sample numbers were $1977(n=3) ; 1987(n=11) ; 1997(n=46)$; 2007 ( $n=90)$; and $2017(n=220)$. The full corpus from 1977-2017 comprised 370 articles.

We entered these articles into an Excel spreadsheet, eliciting details in the following headings from the abstract and, where this was missing, the main article: author(s); title; journal; year; epistemological stance (functionalist/critical); empirical or conceptual; theory used; focus of research; site of research; main participant group; methodology; main methods of data generation and analysis; geographical location of analysis. Our decision to generate data concerning epistemological stance is prompted by significant previous mapping that foregrounds this dimension (e.g. Gunter, 2001, 2005, 2016; Gunter and Ribbins, 2002; Ribbins and Gunter, 2002). Whilst we acknowledge the plurality of categorisations in such mapping, we drew primarily on Gunter's (2016) summary of knowledge purposes, but collapsed her four categories into two, as follows. Gunter's situational and functional types share a rationale focused on delivery, and so we operationalised these as 'functionalist'. Gunter's realist and activist types are concerned with democratising, and so we operationalised these as 'critical'. We see these as congruent with her functionalist/socially critical categorisations outlined above. As we read, we gained an impression of the quality of the scholarship and the plausibility of a given author's claim to be, for example, using theory or examining power relations, and noted this for our qualitative strand. We take our working definition of theory from Anyon (2009: 3), for whom it is 
[a]n architecture of ideas - a coherent structure of interrelated concepts - whose contemplation and application (1) help us to understand and explain discursive and social phenomena and (2) provides a model of the way that discourse and social systems work and can be worked upon.

Using this definition has two main implications. First, unlike in the natural sciences or philosophy, theory here does not claim predictiveness and posits nothing; it illuminates, explains and models. Second, all human utterances and actions are informed by such a conceptual architecture, acknowledged or otherwise. Theory is deeply embedded into the way we see and move through the world and, subsequently, the way we design and conduct research. Therefore, when we refer below to atheoretical research, we are writing specifically about mostly functionalist scholarship that rejects that second implication, claiming instead that education interventions, actions and policies might be informed almost wholly by empirical evidence of 'what works', which is constructed as value-free and objective. This overlooks the extent to which the selection of which questions to ask, or how to frame them, is first influenced by perhaps unarticulated education and social theories.

Our position is therefore that education research has an obligation to make transparent and explicit its theoretical underpinnings, for scrutiny and to locate the analysis. For the output categorisation, we took authors' statements concerning whether they used theory at face value, but we came to our own judgement about the skill with, or the depth to which we saw theory had been put to work within a paper, and its concomitant usefulness. Our criteria here comprised explicitness; sophistication; theory work (as opposed to deployment); and evidence of a theoretical contribution. Our judgements reflect our positioning as critical scholars; undoubtedly, school-effectiveness researchers would have come to different conclusions. We see this not as evidence of a bias to be eradicated, but of self-reflectivity, which, as critical sociologists of educational leadership, is an integral aspect of trustworthiness.

Our final point concerning our methodological approach is that we see this contribution as an exploratory partial corrective to the recent turn to bibliometric approaches to mapping the field (Hallinger, 2020). We refute the notion that this is the best way to know the field; we insist on the important role of qualitative, subjective interpretation in typologising and mapping, and relish those moments of contestability in the outcomes. These judgements, especially concerning quality, are ours alone.

\section{Limitations}

Our approach, like all others (see e.g. Thomson, 2017), produces a snapshot of the field and does not claim exhaustiveness. We have addressed limitations in other mappings (i.e. concerning the site of publication and the lack of longitudinality) but created new ones for others to address in turn. These include the following: our approach relies on titles containing the key words, so those relevant articles omitting variations of the word 'leadership' were not returned. Many abstracts were so poorly constructed that eliciting the necessary information was challenging, and the results sometimes contestable. In these instances, we discussed the article as a team to arrive at a consensus. Our approach of sampling one year out of each decade inevitably meant that contemporaneously active researchers may well have been missed. However, complete coverage was never our intention, and we have no reason to believe that the years selected were particularly atypical. Moreover, we ran the analysis for the cohorts from the 1970s to the 2000s using a two-year window, and the results did not differ significantly. Finally, we depended for our sample on the 'black box' of Scopus' algorithm: we could see instances where returns or omissions did not make sense to us, but could not interrogate these. 


\section{0-year trends in educational-leadership research}

In this section, we present our findings and analysis of trends in educational-leadership research in the 50 years between the 1970 s and the 2020 s.

\section{Increase in empirical research}

The proportion of empirical studies increased steadily over time, rising from $67 \%$ of the sample in 1977 (i.e. two out of three articles) to 80\% of the studies sampled in 2017. The trajectory of empirical research represented within the sample represents ebbs and flows over the 50 years, but indicates an increasing dominance of empirical work in recent decades. The 1987 and 1997 samples saw a dip in the proportion of empirical work, with $55 \%$ of the papers in 1987 and $48 \%$ of the papers in 1997 presenting empirical research. This proportion grew significantly into 2007 (70\%) and 2017 (80\%). These findings reflect Hallinger and Chen's (2015) assertion that, globally, educational-leadership researchers have become more engaged in empirical research.

\section{Diversification of approaches to research (method and analysis)}

Alongside an increase in empirical work was a significant diversification of method and approaches towards analysis.

The sample from 1977 solely included survey-based research. The 1980s saw the use of surveys continue, with one article that drew also on interview data. The trend for surveys and interviews continued to the 1990s, though the methods expanded to also include articles that drew on autoethnographies and narratives. The 2000s and 2010s marked a clear shift towards more diverse methods of data generation, though surveys and interviews remained a dominant method (and continue to do so). This trend reflects Thomson's (2017) snapshot mapping of research methods within ELMA. Researchers in the 2000s sample, where $24 \%$ of the papers drew on diverse research methods, undertook new approaches including participant journalling and writing, mapping activities, performances, and network analyses. The proportion of studies that incorporated diverse research methods in the $2010 \mathrm{~s}$ was reduced to $11 \%$. The sample from the $2010 \mathrm{~s}$ represented a shift towards more diverse methods of data generation including observations, policy analyses, and analyses of forum posts or other forms of participant writing.

Data-analysis methods have also diversified. The 1970s, 1980s and 1990s were represented largely by statistical analyses, and the 2000s and 2010s brought in other methods including discourse analysis and various forms of thematic coding of qualitative data. By the 2010s, a large proportion of the analysis was being undertaken through different forms of thematic coding. However, data analysis in ELMA research raises concerns: even in the sample of articles from the 2010 s, approximately $25 \%$ did not indicate their approach to analysis. This was consistent in the 2000s and 1990s as well, suggesting a need to increase the visibility of analysis methods within research publications.

\section{Theory in educational-leadership research}

Our data reveal that, although the use of theory has become somewhat more diverse and explicit over the 50-year period, it often remains implicit and uninterrogable. It certainly rarely responds to Ribbins and Gunter's (2002) call for theorisations that challenge and unsettle assumptions. 
Overwhelmingly, each decade's sample included more papers that held no mention of theory than those that did, except for 2007 's sample, where $51 \%$ of the articles mentioned either theory or a 'framework'.

The trends over the 50-year period reflect field history. Hallinger and Chen (2015) noted the atheoretical nature of early educational-leadership research, a trend our findings support, with no mention of theory in our 1970s sample. This reflects the dominance of the Theory Movement in the 1960s and 1970s, whose eponymous theory was organisational systems theory (Gunter, 2020); this drew on a positivist epistemology to privilege investigations of effective leader behaviours. Greenfield (1974) produced a challenge to the field to adopt instead 'an interpretive and co-constructivist ontology and epistemology for thinking about the reality of decision-making' (Gunter, 2020: 39), that is, one that required explicit theorisation to illuminate and explain subjects' conceptualisations of their leadership roles, identities and practices. This challenge was increasingly taken up over the 50 years of research we reviewed. The 1980 s saw a slight increase with $27 \%$ of papers having an explicit mention of theory. The 1990s (24\%) saw more theory, with an increase in qualitative approaches, though there was still a large proportion of atheoretical papers regardless of research paradigm. The 2000 s represented the first decade where most of the articles included some alignment with theory (51\%), though this was frequently a brief mention of a theorist with no other detail or information about how that theory had been put to use in the research. The trend began to reverse in the 2010 s, with only $46 \%$ of articles mentioning theory.

We therefore extend Thomson's (2017) suggestion that the field 'largely takes its [methods] tools for granted' to the use of theory within the field, that is, that theoretical tools are largely unscrutinised and rarely developed. We go further: no researcher would claim to be able to do without methods tools, but the use of theory seems optional at best. We conclude that theorising and the use of theory in the ELMA outputs we sampled is generally weak. Stronger articles put theoretical tools to work, such that theory is advanced, or the theoretical tool developed. These were very rare in our sample. More often, where use of a theory was claimed, it was more akin to what Hey (2003) has called 'intellectual hairspray' (n.p.), with typically brief treatments that did not form part of a deeper discussion about the way theory was being used to frame or analyse data. These articles consequently made no substantive or significant theoretical contribution. We have spoken elsewhere of the importance of theoretical 'honesty' (Courtney, McGinity and Gunter, 2017) and the findings of this review further highlight the need for researchers to be explicit when dealing with theory in educational-leadership research. This applies as much to functionalist research as to critical, since, as Heck and Hallinger (2005) note, theoretically informed research is desirable in all paradigms, although they see theory rather differently from Anyon (2009) in privileging those forms that may contribute to cumulative knowledge in educational leadership.

\section{Object of study}

We examined the articles to identify trends across the 50-year period relating to the object of study in educational-leadership research. We found an early dominance of schools and principals as the focal point of the research. Where other participant groups were involved in the project, they were frequently being asked to reflect upon the principal or school leadership more broadly. The sample of papers from the 1970s and 1980s focused almost exclusively on schools, with one paper focused on deans in higher education in the 1980s sample. Of the school-focused articles from these decades, only one of these looked beyond principals towards other conceptualisations of leadership. The 1990s brought an expansion of educational-leadership roles of focus to include higher- 
education leaders, superintendents and teacher leaders, and the sites of research included a focus on postsecondary sites that trained or provided professional development for educational leaders. These conceptualisations of leadership became more diffuse in the 2000s with research that included a focus on system leaders, ICT leaders, curriculum leaders, early-childhood leaders and student leaders. The final sample, representing the 2010s, demonstrated a more explicit focus on educational-leadership research, as well as a continuation of the broader conceptualisation of educational leadership such as a focus on teacher leadership, higher-education leadership and system leadership.

This finding can be interpreted as both healthy and unhealthy for the field. On one hand, the decoupling of leadership, or 'leaderful practice' (Raelin, 2011) from the person at the organisational apex may be conceptually and practically productive, enabling a new focus on relational forms of leadership that acknowledge transient moments of meaning-making that are organisationally and educationally significant, and which may be initiated by anyone in the education institution (see e.g. Eacott, 2014). Two of the three present authors have called elsewhere (Courtney and McGinity, $2020 \mathrm{~b}$ ) for increased awareness of, and research into, such practices, and into the identities of those who undertake them. Our analysis here shows that the field is indeed seeing 'leadership' in more places and performed by more people, but, and in our view less helpfully, the insistence on calling these practitioners 'leaders' may draw them and their practices into an established framing that is limiting rather than liberating, a framing that Courtney and McGinity (2020b) identify as a leader 'character'. Indeed, and this is what we see as unhealthy for the field, our finding here may indicate the discursive spread of leadership as a concept. Practices that had been understood as part of, for instance, teaching, such as standing in front of a class and directing, enabling or guiding learning, have become collocated to leadership in a way that is deprofessionalising to teaching, and adds little of use to leadership. The reason is clear: just as with administration and management before it (Gunter, 2004; Bush, 2008), so now with leadership; much is expected of it, even societal transformation, with decreasing hope of achieving it. Rather than accept the limitations of leadership, our analysis reveals that policymakers, the educational-leadership industry and those whose identities and reputations are located in leadership have expanded the definition, sites and protagonists. This risks reducing, rather than enhancing, its analytical usefulness. (Educational) leadership is in its red giant phase, massively expanding but increasingly unstable.

\section{Dominance of the global north}

Our analysis shows that, over time, the field has internationalised. All the papers in the 1970s and 1980s sample were located within the global north (largely the US, the UK and Australia). In the 1990s batch, $9 \%$ of papers represented countries outside of the global north, including Israel, Cyprus and two that focused on Hong Kong. This increased in the 2000s sample, with $22 \%$ of papers located outside of the global north. Places that were represented multiple times in that sample included Hong Kong, Vietnam, Flanders, Taiwan and the Philippines. Further countries included Nigeria, Turkey and Slovenia. There was a marked increase in the 2010 s, with $25 \%$ of papers from the sample being based or focused on locations other than the global north. They included research from South Africa, Israel, Turkey, China, Sweden, Spain, the United Arab Emirates, Malaysia, France, Thailand, Pakistan and Finland. Hallinger and Chen's (2015) review of trends in ELMA research in Asia noted the 'hidden literature' in countries including those represented in the 2010s sample of this study. They suggested that many papers are written in 
languages other than English, and that the contributions they make to the field are likely overlooked as a result.

There have long been calls that recognise the importance of a more diverse field of educationalleadership research. For example, Wilkinson (2008) highlighted the need for more diverse research perspectives within the field, noting that scholarship frequently overlooked implications and issues of diversity. Niesche and Gowlett (2015) advocate similarly, highlighting the way in which much of the field has marginalised discourses relating to feminism, ethnicity and race. Lopez (2021) has called for educational leadership to be decolonised to challenge western models that dominate research in the field. It is notable that in Thomson's (2017) review of methods in educationalleadership research, EMAL was identified as having the most papers of international authorship, and editorials and special issues that took a deliberately international focus.

\section{Critical and functionalist leadership research}

Typologising educational-leadership research according to the categories of critical or functional, or variations of these, has proved productive. Our analysis shows that critical research was marginal in the earlier years of the sample, but that it has become increasingly well represented. There were no critical research studies represented in the 1970s sample, though this grew to $27 \%$ of papers in the sample from the 1980s. This proportion decreased in the $1990 \mathrm{~s}$, with $13 \%$ of papers representing critical research, but in recent years it has recovered, remaining relatively steady with $31 \%$ of the 2000 s sample, and $28 \%$ of the 2010 s sample aligning with critical perspectives. The increase in recent years tracks the simultaneous increase in articles invoking theory: the critical research by definition includes a focus on power relations and structures, or structured agency, which one would expect to be theorised in some way. The overall proportion of critical research, however, is more than previously suggested or found in bibliometric analyses, even where not named as such (e.g. Hallinger and Kovačević, 2021) and reflects the relatively large numbers of primarily American educational-leadership research articles that focus on issues of race.

\section{Sites of publication}

Our finding above concerning the unexpectedly higher proportion of critical research can be explained by taking into account our novel sampling strategy of looking outside the major educational-leadership journals. When the research field is constructed as being confined to these, there is a consistent finding from previous mapping activities that shows that critical research sits at the margins of the field (Wilkinson and Eacott, 2013), with most educational-leadership researchers focusing instrumentally and normatively upon raising standards in education through identifying effective leadership behaviours or activities (see Gunter, 2016; Thomson, 2017). Importantly, the findings over the 50-year period showed that the field is scattered beyond only those journals that focus on educational leadership. Critical research particularly is increasingly being published outside of the core leadership journals. The sample from the 1970s and 1980s represented the largest proportion of research being published within leadership-focused journals, with $66 \%$ and $54 \%$ of papers respectively being published in key leadership journals including NASSP Bulletin, School Leadership \& Management and Educational Administration Quarterly. That proportion decreased in the following decades. Only $48 \%$ of articles in the 2010 s sample were published in leadership journals, with multiple articles published in Educational Management Administration \& Leadership, Educational Administration Quarterly, International Journal of 
Leadership in Education, Journal of Educational Administration and History and Leadership \& Policy in Schools. Of the non-leadership journals that were evident, some were expected, such as Research in Higher Education, School Effectiveness and School Improvement, and more generalist journals including Educational Research, or Australian Journal of Education. Other journals were much more specific and targeted towards niche areas of research, including the Journal of Homosexuality and the Journal of Jewish Education. There are implications for leadership researchers publishing outside leadership journals, with the increasingly scattered nature of the field highlighting the need to be judicious with keywords and titles so that search algorithms will pick up their research. Simultaneously, the number of leadership journals that are represented most within the sample are those with high impact factors, such as Educational Management Administration \& Leadership and Educational Administration Quarterly. Journals with lower impact factors or source normalized impact per paper (SNIP) values are increasingly less represented within the sample. One such journal, NASSP Bulletin, represented a significant portion of research in the 1970s-1990s but holds very few articles from the 2000s and 2010s samples. Our research findings suggest that the field of 'desirable' leadership journals is narrowing over time.

We anticipate that the trend of leadership research being published outside of the core journals is also reflective of imperatives from universities that limit or direct where academics are allowed or encouraged to publish their work. What 'counts' as a publication is increasingly narrowed, with directives to publish in 'approved' journals that meet narrowly defined criteria including Q-rankings, impact factor or SNIP, or other measures of high status. These ways of regulating academic labour are commonly found in universities around the world and have steered academics towards managerialist targets and metrics (Butler and Spoelstra, 2014). This is a particularly pressing issue for early-career academics (Malsch and Tessier, 2015), who have reported being rewarded or penalised depending on where they publish (Haddow and Hammarfelt, 2019).

We predict that these methods of governing academic work will result in academics publishing their work more often in higher-ranked generalist journals rather than in more relevant, but lowerranked, leadership-specific journals, given the field's relatively small number of journals that meet the traditional definitions of 'quality' (impact factor, Q-ranking, or SNIP). Research from other fields has shown that lower-ranked journals are seeing a diminished quality and number of submissions (Northcott and Linacre, 2010) due to the focus on 'quality' via simplistic measurements. Critical-management researchers, for instance, have noted the focus on quantitative measures of an article's success over other measures of quality (Butler and Spoelstra, 2014).

\section{Conclusion}

Our analysis of these data enables us to make four strong observations about educationalleadership research in English-language journals over the last 50 years.

First, we insist that epistemology matters and ought to feature explicitly in educationalleadership research. Differing epistemological traditions influence the standpoint adopted in a range of proxy issues. For instance, Heck and Hallinger's (2005) reflection on the field from almost 20 years ago suggested that the diversification of research methods and theoretical perspectives was cause for concern, leading researchers who employ different methods to answer different questions to work in parallel streams of research that do not necessarily engage with each other's research. We suggest that diversification is an effect of the field's range of epistemologies; we follow Eacott (2017) in seeing this as a sign of field health rather than a problem. Much critical research, for instance, will never 'build upon' functionalist insights because it is asking different 
questions based on different assumptions about how the social world operates, and ought to. We agree that mutual engagement across paradigms is both possible and desirable, but are realistic about the likelihood of cumulative knowledge being produced as a result. As critical researchers, we do not understand knowledge in the social sciences as being amenable to accumulation in the same way as, for instance, in pharmacology. Epistemology also matters in terms of field mappings. The dominance of functionalism produces a disposition to investigate the field using particular methods, above all bibliometric, which has the effect of privileging functionalist research. We therefore call for more diversity in approaches to field mapping, and for recognition of different approaches in mutual referencing. Notwithstanding Hallinger and Kovačević's (2021) focus on EMAL's corpus, it is astonishing that they do not reference Gunter's (2016) An Intellectual History of School Leadership Practice and Research in their article that claims to map the intellectual lineage of ELMA.

Second, and related to the above, we have identified here a lack of explicit engagement with, and acknowledgement of, the role of knowledge producers in the process of knowledge production. This is particularly relevant in bibliometric reviews which make claims about the form and function of the field which can quite easily obfuscate contributions and traditions, as well as provide only partial accounts (or none at all) of how such research might further contribute to this problem.

Third, empirical research has become established to the point of privilege. It is now necessary to restate the case for conceptual contributions to the field; to set out what is meant by 'rigour' in such conceptual articles in an age dominated by state-mandated research-quality audit criteria that are, by default, aligned to the empirical. Here, we note that EMAL is pioneering in its record of publishing a higher proportion of high-quality conceptual scholarship than other educationalleadership journals (Hallinger and Kovačević, 2021).

Fourth, we observe that a disproportionate amount of critical scholarship is published in noneducational-leadership journals, which has an effect on the way in which the field sees itself. We therefore urge the field to look outside identified 'leadership' journals in future mappings. This methodological choice has become somewhat reified and unproblematised over the last decade or so, yet, as we have shown, it will not reveal the breadth of research that exists.

\section{Declaration of conflicting interests}

The author(s) declared no potential conflicts of interest with respect to the research, authorship and/or publication of this article.

\section{Funding}

The author(s) received no financial support for the research, authorship and/or publication of this article.

\section{ORCID iDs}

Amanda Heffernan (D) https://orcid.org/0000-0001-8306-5202

Steven J Courtney (D) https://orcid.org/0000-0003-2379-7035

\section{References}

Anyon J (2009) Theory and Educational Research: Toward Critical Social Explanation. New York: Routledge.

Bush T (2008) From management to leadership: semantic or meaningful change? Educational Management, Administration \& Leadership 36(2): 271-288. 
Butler N and Spoelstra S (2014) The regime of excellence and the erosion of ethos in critical management studies. British Journal of Management 25(3): 538-550.

Castillo FA and Hallinger P (2018) Systematic review of research on educational leadership and management in Latin America, 1991-2017. Educational Management Administration \& Leadership 46: 207-225.

Condic KS (2015) Citation analysis of student dissertations and faculty publications in reading and educational leadership at Oakland University. The Journal of Academic Librarianship 41(5): 548-557.

Courtney SJ and McGinity R (2020a) System leadership as depoliticisation: Reconceptualising educational leadership in a new multi-academy trust. Educational Management, Administration and Leadership. Advance online publication. DOI: 10.1177/1741143220962101

Courtney SJ and McGinity R (2020b) Conceptualising constructions of educational-leader identity. In: Heffernan A and Niesche R (eds) Researching Identity and Subjectivity in Educational Leadership. London: Routledge, 8-23.

Courtney SJ, McGinity R and Gunter H (eds) (2017) Educational Leadership: Theorising Professional Practice in Neoliberal Times. London/New York: Routledge.

Eacott S (2014) Educational Leadership Relationally: A Theory and Methodology for Educational Leadership, Management and Administration. Rotterdam: Sense Publishers.

Eacott S (2017) A social epistemology for educational administration and leadership. Journal of Educational Administration and History 49(3): 196-214.

Erickson DA (1979) Research on educational administration: the state-of-the-art. Educational Researcher 8(3): 9-14.

Eyal O and Rom N (2015) Epistemological trends in educational leadership studies in Israel: 2000-2012. Journal of Educational Administration 53(5): 574-596.

Greenfield TB (1974) Theory in the study of organizations and administrative structures: a new perspective. Paper presented at the annual meeting of the international Intervisitation Programme on educational administration (Bristol, England, July 1974).

Gümüş S, Arar K and Oplatka I (2021) Review of international research on school leadership for social justice, equity and diversity. Journal of Education Administration and History 53(1): 81-99.

Gumus S, Bellibas MS, Esen M and Gumus E (2018) A systematic review of studies on leadership models in educational research from 1980 to 2014. Educational Management Administration \& Leadership 46: 25-48.

Gunter H and Ribbins P (2002) The field of educational leadership: studying maps and mapping studies. British Journal of Educational Studies 51(3): 254-281.

Gunter HM (2001) Critical approaches to leadership in education. Journal of Educational Enquiry 2(2): 94-108.

Gunter HM (2004) Labels and labelling in the field of educational leadership. Discourse: Studies in the Cultural Politics of Education 25(1): 21-41.

Gunter HM (2005) Conceptualizing research in educational leadership. Educational Management Administration \& Leadership 33(2): 165-180.

Gunter HM (2006) Knowledge production in the field of educational leadership: a place for intellectual histories. Journal of Educational Administration and History 38(2): 201-215.

Gunter HM (2012) The field of educational administration in England. British Journal of Educational Studies 60(4): $337-356$.

Gunter HM (2016) An Intellectual History of School Leadership Practice and Research. London: Bloomsbury.

Gunter HM (2020) Forgetting our shared intellectual histories and the implications for educational professionals. In: Moos L, Nihfors E and Paulsen J (eds) Re-Centering the Critical Potential of Nordic School Leadership Research: Fundamental but Often Forgotten Perspectives. Cham: Springer, 37-52. 
Haddow G and Hammarfelt B (2019) Quality, impact, and quantification: indicators and metrics use by social scientists. Journal of the Association for Information Science and Technology 70(1): 16-26.

Hallinger P (2011) Leadership for learning: lessons from 40 years of empirical research. Journal of Educational Administration 49(2): 125-142.

Hallinger P (2020) Science mapping the knowledge base on educational leadership and management from the emerging regions of Asia, Africa and Latin America, 1965-2018. Educational Management Administration and Leadership 48(2): 209-230.

Hallinger P and Chen J (2015) Review of research on educational leadership and management in Asia: a comparative analysis of research topics and methods, 1995-2012. Educational Management Administration \& Leadership 43(1): 5-27.

Hallinger P and Kovačević J (2019) A bibliometric review of research on educational administration: science mapping the literature, 1960 to 2018. Review of Educational Research 89(3): 335-369.

Hallinger P and Kovačević J (2021) Mapping the intellectual lineage of educational management, administration and leadership, 1972-2020. Educational Management Administration \& Leadership. Advance online publication. DOI: 10.1177/17411432211006093

Harris A (2013) Distributed leadership: friend or foe? Educational Management Administration \& Leadership 41(5): 545-554.

Heck RH and Hallinger P (2005) The study of educational leadership and management: where does the field stand today? Educational Management Administration \& Leadership 33(2): 229-244.

Hey V (2003) Identification \& mortification in late modernity: new Labour; alpha femininities \& their dis/ contents. Keynote Address at the 2003 International Conference of Gender \& Education, University of Sheffield.

Jackson KM (2019) A review of research methods trends in educational leadership journals. ICPEL Education Leadership Review 20(1): 119-132.

Lopez AE (2021) Decolonizing Educational Leadership: Exploring Alternative Approaches to Leading Schools. London: Palgrave Macmillan.

Malsch B and Tessier S (2015) Journal ranking effects on junior academics: identity fragmentation and politicization. Critical Perspectives on Accounting 26: 84-98.

Murphy J, Vriesenga M and Storey V (2007) Educational Administration Quarterly, 1979-2003: an analysis of types of work, methods of investigation, and influences. Educational Administration Quarterly 43: 612-628.

Niesche R (2018) Critical perspectives in educational leadership: a new 'theory turn'? Journal of Educational Administration and History 50(3): 145-158.

Niesche R and Gowlett C (2015) Advocating a post-structuralist politics for educational leadership. Educational Philosophy and Theory 47(4): 372-386.

Northcott D and Linacre S (2010) Producing spaces for academic discourse: the impact of research assessment exercises and journal quality rankings. Australian Accounting Review 20(1): 38-54.

Oplatka I (2009) The field of educational administration: a historical overview of scholarly attempts to recognize epistemological identities, meanings and boundaries from the 1960s onwards. Journal of Educational Administration 47(1): 8-35.

Oplatka I and Arar KH (2017) The research on educational leadership and management in the Arab world since the 1990s: a systematic review. Review of Education 5: 267-307.

Raelin J (2011) From leadership-as-practice to leaderful practice. Leadership 7(2): 195-211.

Raffo C and Gunter HM (2008) Leading schools to promote social inclusion: developing a conceptual framework for analysing research, policy and practice. Journal of Education Policy 23(4): 397-414. 
Ribbins P and Gunter HM (2002) Mapping leadership studies in education: towards a typology of knowledge domains. Educational Management \& Administration 30(4): 359-385.

Royal Geographical Society (undated) A 60 second guide to... The Global North/ South Divide. Royal Geographical Society with IBG. Available at: https://www.rgs.org/schools/teaching-resources/60-sec ond-guide-to-global-north-south-divide/ (accessed 3 June 2021).

Szeto E, Tai Hoi Lee T and Hallinger P (2015) A systematic review of research on educational leadership in Hong Kong, 1995-2014. Journal of Educational Administration 53(4): 534-553.

Thomson P (2017) A little more madness in our methods? A snapshot of how the educational leadership, management and administration field conducts research. Journal of Educational Administration and History 49(3): 215-230.

Walker A and Hallinger P (2015) A synthesis of reviews of research on principal leadership in East Asia. Journal of Educational Administration 53: 554-570.

Wang Y, Bowers AJ and Fikis DJ (2017) Automated text data mining analysis of five decades of educational leadership research literature: probabilistic topic modelling of EAQ articles from 1965 to 2014. Educational Administration Quarterly 53: 289-323.

Wilkinson J (2008) Good intentions are not enough: a critical examination of diversity and educational leadership scholarship. Journal of Educational Administration and History 40(2): 101-112.

Wilkinson J and Eacott S (2013) These disruptive times: rethinking critical educational leadership. International Journal of Leadership in Education 16(2): 135-138.

York-Barr J and Duke K (2004) What do we know about teacher leadership? Findings from two decades of scholarship. Review of Educational Research 74: 255-316.

\section{Author biographies}

Ruth McGinity is an associate professor of educational leadership at the Institute of Education, UCL, UK. Ruth's research is organised around three main themes and seeks to critically investigate new models and structures of schooling, theorise professional identities and practices and explore knowledge production within and for the field of educational leadership.

Amanda Heffernan is a senior lecturer in leadership in the Faculty of Education at Monash University in Melbourne, Australia. In 2019 she was awarded the Hedley Beare Award for Educational Writing from the Australian Council for Educational Leaders, for an outstanding piece of educational leadership writing that has made a significant contribution to the field. Amanda's work takes a critical perspective towards school leadership, education policy and the everyday experiences of educational leaders' work. Her book, The Principal and School Improvement: Theorising Discourse, Policy, and Practice, was published in 2018.

Steven J Courtney is senior lecturer in management and leadership and research coordinator at the Manchester Institute of Education, University of Manchester, UK. He uses critical sociological approaches to explore the interplay between agency and structure in education policy and leadership. His research has been recognized with awards from AERA Division A, BERA, BELMAS and the British Academy. In 2021, he co-edited with Helen Gunter, Richard Niesche and Tina Trujillo the textbook Understanding Educational Leadership: Critical Perspectives and Approaches. He is an editor of Critical Studies in Education and a member of BELMAS Council. 